\title{
Amniotic Fluid Volume Assessment: Eight Lessons Learned
}

\author{
Everett F Magann (iD) \\ Julie R Whittington $\mathbb{D}^{1}$ \\ John C Morrison ${ }^{2, \dagger}$ \\ Suneet $\mathrm{P}$ Chauhan $^{3}$ \\ 'Departments of Obstetrics and \\ Gynecology of the University of Arkansas \\ for the Medical Sciences, Little Rock, AR, \\ USA; ${ }^{2}$ Department of Obstetrics and \\ Gynecology of the University of \\ Mississippi Medical Center, Jackson, MS, \\ USA; ${ }^{3}$ Department of Obstetrics, \\ Gynecology and Reproductive Sciences \\ of the University of Texas Health \\ Sciences Center at Houston, Houston, \\ TX, USA \\ ${ }^{\dagger} \mathrm{Dr}$ John C. Morrison passed away on \\ September I, 2019
}

\begin{abstract}
Actual AFV can be determined by a dye-dilution technique or be directly measured at cesarean. This allows investigators to correlate estimated and actual AFVs. Lessons learned by assessing the relationship of estimated to actual AFVs. 1) Ultrasound estimates normal actual AFVs well, but abnormal AFVs poorly. 2) Quantile regression is a better statistical methodology to create a normal AFV curve across pregnancy. 3) There is no difference in the accuracy of the subjective (visualization without measurements) compared with the objective (visualization with measurements) technique in identifying normal and abnormal AFVs. 4) Color Doppler use leads to the over-diagnosis of oligohydramnios. 5) Intravenous hydration increases actual AFVs. 6) The estimation of AFV can be done with the transducer held perpendicular to the floor or perpendicular to the uterine contour. 7) The single deepest pocket should be used for identifying low AFVs. 8) The AFI should be used for identifying high AFVs.
\end{abstract}

Keywords: amniotic fluid volume, oligohydramnios, polyhydramnios, color Doppler, subjective assessment, objective assessment

\section{Introduction}

Ultrasound poorly estimates actual abnormal AFS, quantile regression creates normal AFV curves, subjective and objective AFVs are similar, color Doppler overestimates oligohydramnios, single deepest pocket should be used for oligohydramnios and AFI for polyhydramnios estimations.

\section{Lesson I: Does Ultrasound Estimate of the Amniotic Fluid Volume (AFV) Correlate with the Actual (Dye-Determined or Directly Measured) Amniotic Fluid Volume?}

The actual AFV can be determined by dye-dilution techniques or the volume can be measured at the time of a cesarean delivery. The dye-dilution techniques are invasive and require laboratory support to determine the actual AFV, or if the AFV is directly measured, it can only be done at the time of delivery. Both of these techniques, dyedilution technique by amniocentesis and direct measurement of collected amniotic fluid volumes at cesarean have been shown to have good correlation $(r=0.99, p=$ $<0.001)$ and both volume determinations are representative of the actual AFVs and can both be used to determine the actual volumes of amniotic fluid. ${ }^{9}$ There are a limited number of investigators who have compared the ultrasound estimates of amniotic fluid volume (AFV) (amniotic fluid index (AFI) and single deepest pocket
Correspondence: Everett F Magann

Department of Obstetrics and Gynecology of the University of Arkansas for the Medica Sciences, 430 I W. Markham St. Slot \# 5 I8, Little Rock, AR, 72205, USA

Tel + I 50I-686-8345

$\mathrm{Fax}+\mid$ 50I-526-7820

Email efmagann@uams.edu 
(SDP) techniques) to actual AFVs determined at the time of amniocentesis by the dye-dilution technique or volume collected and directly measured at cesarean delivery. ${ }^{1-8}$ These Investigators have observed that the ultrasound estimated AFVs are moderately accurate in the identification of actual normal AFVs, but poorly identify abnormal AFVs (oligohydramnios and polyhydramnios). The dilemma for the clinician is that ultrasound estimates of AFVs are being undertaken to identify actual abnormal amniotic fluid volumes, not normal volumes, and the use of ultrasound to identify oligohydramnios and polyhydramnios is inadequate.

Lesson learned: The ultrasound estimate of AFV identifies normal AFV well, but abnormal volumes (oligohydramnios and polyhydramnios) poorly.

\section{Lesson 2: What is a Normal Amniotic Fluid Volume?}

The importance of accurately identifying a normal (AFV) is that without defining normal, you cannot identify what is abnormal. A number of investigators have assessed AFVs of normal pregnancies using dye dilution techniques or direct measurement at the time of cesarean delivery. ${ }^{10,11}$ These AFVs from normal pregnancies at different gestational ages are used to create a normal AFV curve across gestation. Abnormal fluid volumes are usually defined as volumes that are $<5 \%$ or $>95 \%$ for each gestational age of interest. Different statistical methodologies have been used to create these normal curves during pregnancy. These normal curves are similar overall but tend to have wide ranges of normality at the extremes of gestational age where data points are few. More recently, quantile regression has been used to create a curve of normal amniotic fluid volume across pregnancy ${ }^{12}$ (Figure 1). Compared to other statistical methods, quantile regression relaxes the stringent assumptions using regression models and overcomes the limitations of those models at the extremes of gestational age where data points for the AFV are few. This is important because when data points are plentiful, the different statistical methodologies produce similar normal AFV curves. However, at the extremes of gestational age, when data points are few, quantile regression calculates the amniotic fluid for each gestational age of interest. Other statistical methods create smooth curves even when few data points are available, resulting in false-positive abnormal AFVs.

Lesson learned is quantile regression should be used in creating normal amniotic fluid volume curves across pregnancy.

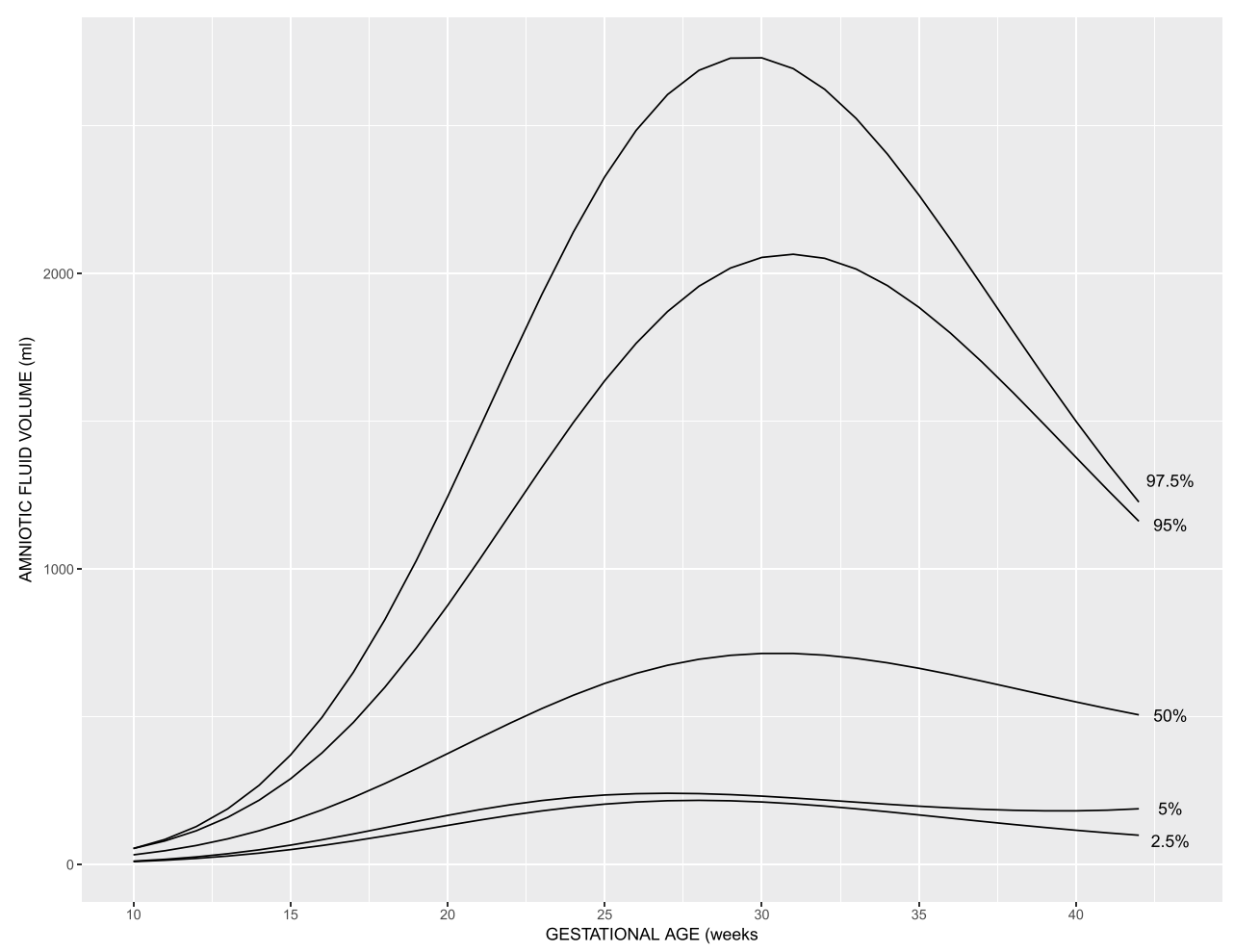

Figure I Normal amniotic fluid volume across gestation using quantile regression. 


\section{Lesson 3: Is There a Difference in the Subjective vs Objective Assessment of AFV?}

A subjective assessment of an AFV is an evaluation of that fluid volume by an experienced clinician without taking ultrasound measurements of the AFV. A study was undertaken with 63 singleton pregnancies and health care providers with varying experience. This consisted of a second-year OB-GYN resident, a nurse sonographer, a maternal fetal medicine fellow and a maternal fetal medicine staff. ${ }^{13}$ The health care providers scanned the patients, but only subjectively evaluated the AFVs (looked at the volume of fluid, but did no measurements) and determined if the AFV was low, normal, or high. The principal investigator then estimated the AFV using the AFI and SDP techniques. All the patients underwent amniocentesis and the actual AFV was determined by dye-dilution technique. The subjective and objective assessments were compared to actual AFVs determined by dye-dilution technique. Normal and abnormal fluid volumes were similarly identified by subjective and objective assessments and no differences in accuracy of this assessment was observed based on the health care provider experience.

Lesson learned: The subjective assessment (visual assessment without measurements) is equivalent to the objective assessment (measurements using the AFI and SDP) in identifying low, normal, and high AFVs.

\section{Lesson 4: What is the Role of Color Doppler in the Assessment of Amniotic Fluid Volume?}

In the estimation of the AFV, the largest vertical pocket of fluid free of umbilical cord or fetal small parts with horizontal measurement of at least $1 \mathrm{~cm}$ is measured and recorded in each of the 4 quadrants divided by the umbilicus into upper and lower quadrants and by the linea nigra into right and left halves (AFI). The SDP is the measurement of the largest pocket of amniotic fluid without fetal small parts or umbilical cord visualized. With the introduction of color Doppler, the umbilical cord could often be seen in the measured fluid pockets that could not be seen by using gray scale alone. See (Figures 2 and 3) for examples of measurments using gray scale vs. color Doppler. Since pockets containing cord should not be measured, using color Doppler should improve the detection of oligohydramnios. Several investigators have shown that when color Doppler is compared to gray scale, the ultrasound measurement of the AFI and SDP are decreased by approximately
$20 \%$. But does the use of color Doppler actually improve the detection of actual oligohydramnios? One study has compared gray scale vs color Doppler in the detection of actual (dyedetermined) oligohydramnios. ${ }^{14}$ AFV was estimated by the AFI and SDP in 67 pregnancies. The average AFI was 11.6 using gray scale and 9.3 using color Doppler. The average SDP was 4.5 using gray scale and 3.7 using color Doppler. Actual dye-determined volumes were then determined. The color Doppler did not accurately identify any more of the actual pregnancies with oligohydramnios compared with gray scale but did reclassify 9 normal actual volumes as having oligohydramnios. The study concluded that color Doppler use leads to the over diagnosis of oligohydramnios.

Lesson learned: Color Doppler should not be used in the assessment of amniotic fluid volume.

\section{Lesson 5: Does Maternal Hydration Have an Effect on Amniotic Fluid Volume?}

Maternal oral and intravenous hydration have been linked with increases in ultrasound-estimated AFVs. Is there information on whether actual AFVs are increased by maternal hydration? We could find no literature where actual AFV has been calculated before and after hydration. We undertook an investigation to determine if actual volumes increased with maternal hydration. ${ }^{15}$ Women undergoing an elective cesarean section with uncertain fetal maturity status were recruited. An AFI was obtained prior to the amniocentesis and the AFV was measured using the dye dilution technique after the fluid was withdrawn for fetal maturity studies. In 17 women, the fetal maturity studies were mature. These patients were hydrated with $1000 \mathrm{~mL}$ of a balanced salt solution 30 minutes prior to her cesarean delivery. AFV was again estimated with an AFI just prior to the cesarean delivery. At the time of the cesarean, the AFV was directly measured and compared with the dye-determined volume. The pre-hydration and post-hydration AFV estimates using the AFI were also compared. The median AFI prior to the hydration was 8.6 (range 5.8-17.8) with a median increase of $1.7 \mathrm{~cm}(95 \%$ CI $1.1,3.0$; P < 0.01). The pre-hydration actual amniotic fluid volume was $450 \mathrm{~mL}$ (range 250-953 m) and the median increase in the actual amniotic fluid volume was $188 \mathrm{~mL}(95 \%$ CI 60-254 mL; P < 0.001).

Lesson learned: The infusion of a balanced salt solution not only increases the AFI but the actual AFV as well. 


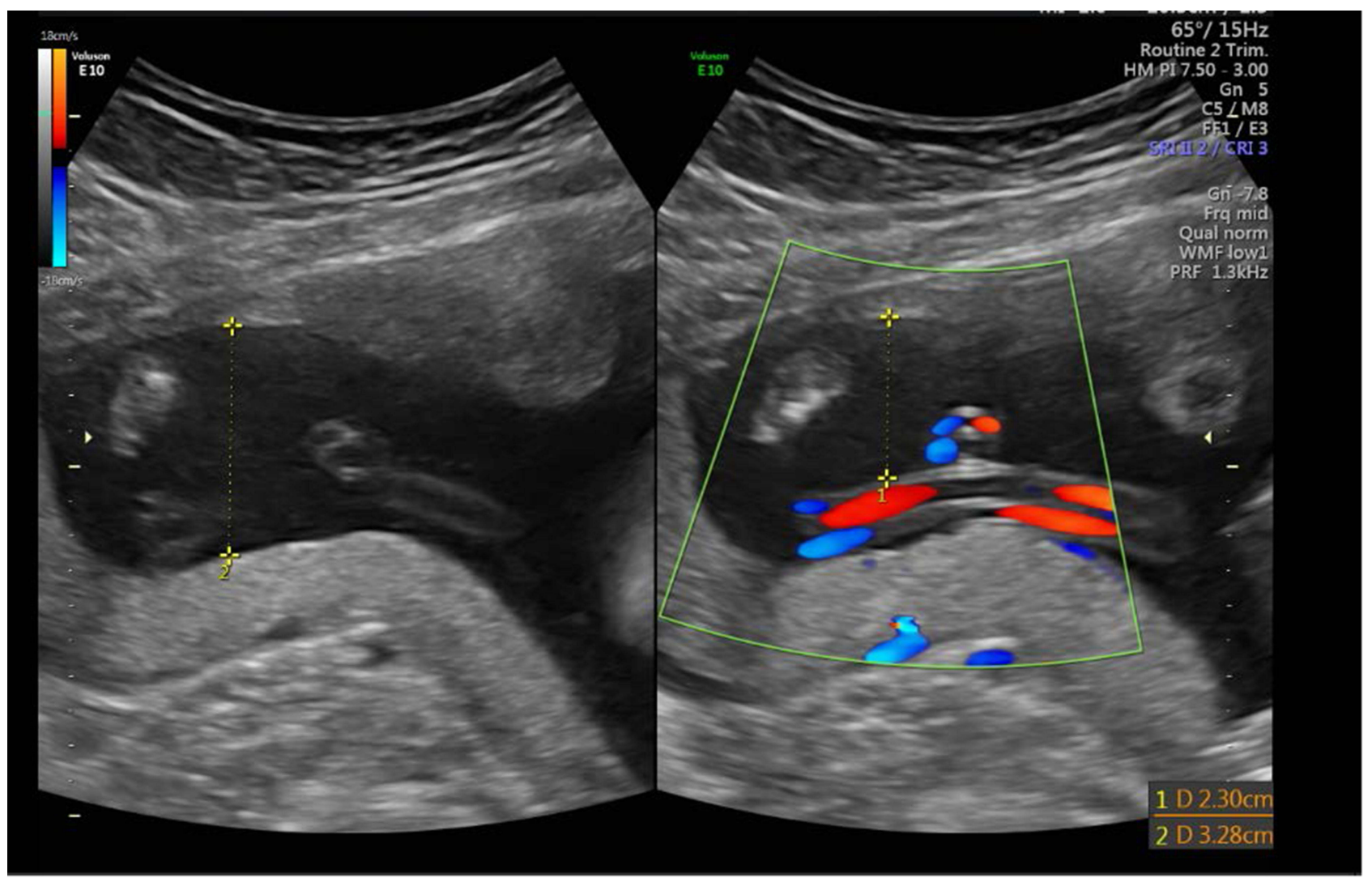

Figure 2 Example $A$ of the assessment of amniotic fluid volume using gray scale on the $L$ side of the screen and color Doppler on the $R$ side of the screen and measurement of the amniotic fluid pocket.

\section{Lesson 6: When}

\section{Ultrasound-Estimating the AFV, Should the Transducer Be Held Perpendicular to the Floor or Perpendicular to the Uterine \\ Contour?}

Two methods on how to hold the ultrasound transducer when measuring the AFI/SDP have been described. One method is to hold the transducer perpendicular to the floor and the other is to hold the transducer perpendicular to the uterine contour. Is there a difference in the measurements between the two techniques of holding the transducer? A single investigation has compared these two techniques in 240 patients ( 20 patients at each gestational age) from 28 to 40 weeks. ${ }^{16}$ The investigators observed no statistically significant difference between the two approaches for the AFI or SDP measurements. Either method (perpendicular to the floor or perpendicular to the uterine contour) may be used.

Lesson learned: The ultrasound probe may be held perpendicular to the floor or perpendicular to the uterine contour during the third trimester of pregnancy when ultrasound estimating the AFV.

\section{Lesson 7: Identification of Low AFV: AFI vs SDP}

In an investigation of 500 post-term pregnancies, if the AFI was used to measure the AFV, $10 \%$ of those pregnancies would be labeled as having oligohydramnios compared to only $2 \%$ if the SDP was used. ${ }^{17}$ AFI use led to more labor inductions, and a trend towards more cesareans without any improvement in perinatal outcomes. A study compared the use of the AFI (273 pregnancies) vs the SDP (264 pregnancies) as the estimated fluid components of the biophysical profile (BPP) in at-risk pregnancies. The study determined that using the AFI $38 \%$ of the pregnancies would be labeled as having oligohydramnios compared to $15 \%$ if the SDP was used. ${ }^{18}$ The use of the AFI led to more labor inductions without any difference in intrapartum and perinatal outcomes. A third study compared the intrapartum assessment of AFV upon a labor and delivery admission. ${ }^{19}$ There were 499 women in the AFI group and 


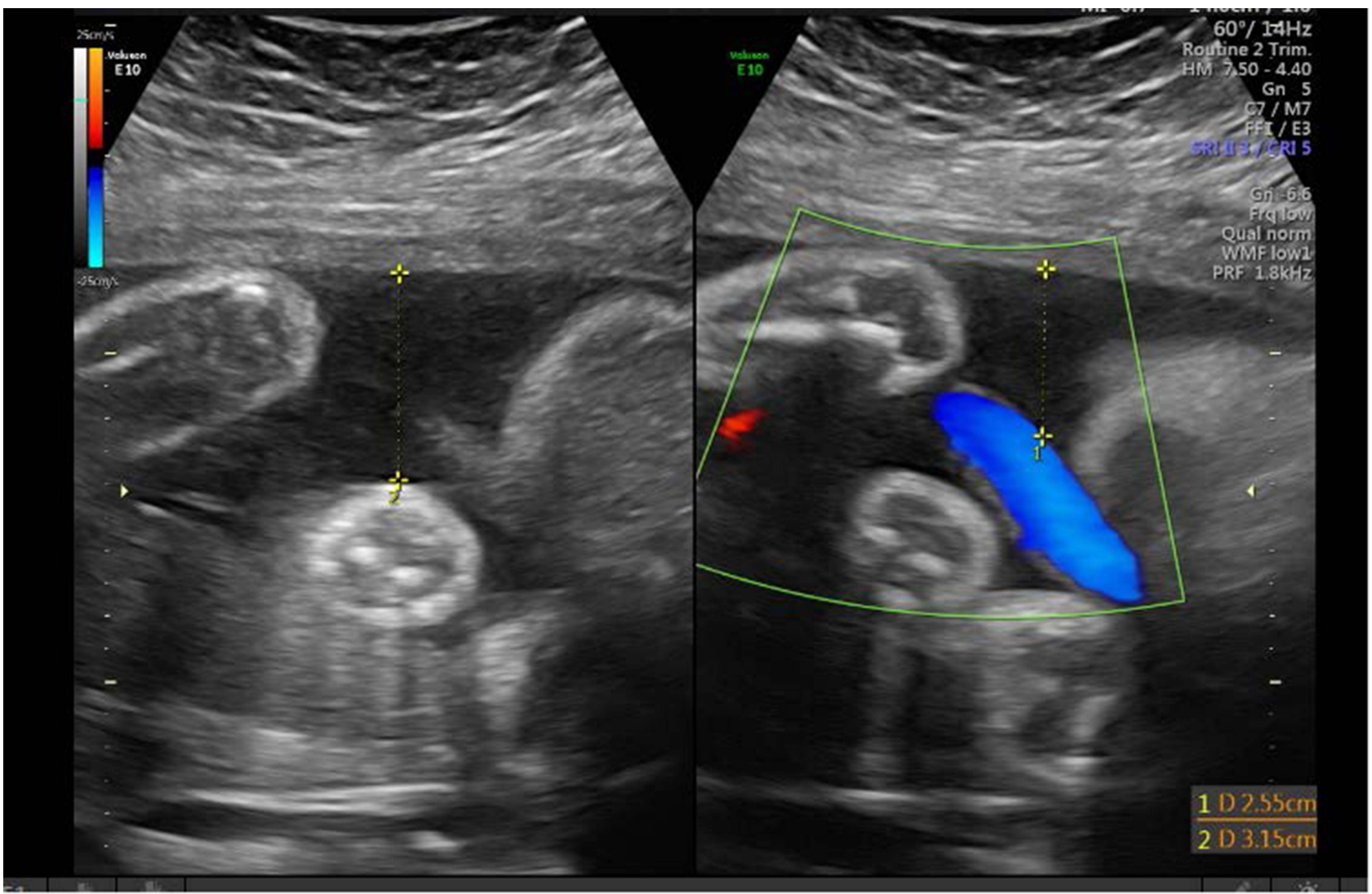

Figure 3 Example $B$ of the assessment of amniotic fluid volume using gray scale on the $L$ side of the screen and color Doppler on the $R$ side of the screen and measurement of the amniotic fluid pocket.

501 in the SDP group. More women were labeled as having oligohydramnios in the AFI group 25\% compared with the SDP group (8\%). Neither test could identify a pregnancy at-risk for an adverse intrapartum or perinatal outcome. A fourth study of at-risk pregnancies compared women undergoing antenatal testing with the non-stress test and using the AFI (530 pregnancies) and SDP (558 pregnancies) as the fluid component of the testing. ${ }^{20}$ More women were labeled as having oligohydramnios with the AFI (17\%) compared with the SDP (10\%). There were no differences in intrapartum and perinatal outcomes between the groups. A fifth trial (SAFE trial) of 1052 singleton pregnancies compared the AFI and SDP for predicting adverse pregnancy outcomes. In comparing the use of the AFI compared to the SDP, the use of the AFI led to more pregnancies being labeled as having oligohydramnios (9.8\%) vs (2.2\%) [RR, 4.51 (95\% CI, 2.2-8.57); P < $0.01]$, more labor inductions for oligohydramnios (12.7\%) vs (3.6\%) [RR, 3.50 (95\% CI, 1.76-6.96); $\mathrm{P}<$ 0.01 ] and more abnormal fetal heart rate tracings (32.3\%) vs (26.2\%) [RR, 1.23 (95\% CI, 1.02-1.50); $\mathrm{P}=0.03]$. Other pregnancy outcomes were similar. ${ }^{21}$ A Cochrane
Database Syst Rev in 2008 concluded that the SDP was a better choice for the assessment of the AFV during fetal surveillance because the use of the AFI increased the diagnosis of oligohydramnios and labor inductions without improvement in perinatal outcomes. ${ }^{22}$

Lesson learned: The SDP should be used for the identification of oligohydramnios.

\section{Lesson 8: Identification of High Amniotic Fluid Volumes: AFI vs SDP}

A study compared the accuracy of the AFI and SDP for the identification of oligohydramnios, normal amniotic fluid volume and polyhydramnios in 506 dye determined or directly measured amniotic fluid volumes using volumes from normal pregnancies calculated by quantile regression. ${ }^{8}$ Both the AFI and the SDP identified actual normal AFVs with a sensitivity that is $>90 \%$. Of the 39 pregnancies with actual polyhydramnios, the AFI identified 9 correctly but falsely identified 11 normal fluid volumes as polyhydramnios. The SDP correctly identified 
11 of the actual polyhydramnios fluid volumes but falsely identified 24 normal fluids as polyhydramnios. The AFI had a higher positive predictive value for polyhydramnios (55\%) compared to the SDP technique (31\%, P=NS) and a lower missed call rate for polyhydramnios than the SDP (OR 5.5; 95\% CI 2.04-14.97) compared to the SDP. It appears that the use of the AFI is superior to the SDP for the identification of polyhydramnios.

Lesson learned: The AFI should be used for the identification of polyhydramnios due to overestimation with the SDP technique.

\section{Summary}

These 8 simple lessons learned provide clinical guidance to the obstetrician/gynecologist in their utilization of the sonographic estimation of AFVs used multiple times a day in a busy obstetric practice. We provide evidence-based recommendations based on 30 years of AFV research. More research needs to be done in some areas, specifically to determine which ultrasound estimation of AFV should be used, the AFI or the SDP, to determine the link between idiopathic polyhydramnios and adverse pregnancy outcomes.

\section{Acknowledgments}

We thank Donna G. Eastham, BA CRS, for her help in editing, formatting and submitting this manuscript. In memoriam and posthumously submitted by Dr. John C. Morrison, who passed away on Sept 1, 2019. He made significant contributions to the paper in literature review, study design, and manuscript drafting.

\section{Funding}

The authors report no funding for this project.

\section{Disclosure}

Dr. Magann was the co-editor of the chapter on the ultrasound assessment of amniotic fluid volume (Oligohydramnios) and received royalties from UpTo Date. The authors report no other conflicts of interest in this work.

\section{References}

1. Croom CS, Banias BB, Ramos-Santos E, Devoe LD, Bezhadian A, Hiett AK. Do semiquantitative amniotic fluid indexes reflect actual volume? Am J Obstet Gynecol. 1992;167(4 Pt 1):995-999. doi:10.1016/S0002-9378(12)80026-3

2. Dildy GA, Lira N, Moise KJ, Riddle GD, Deter RL. Amniotic fluid volume assessment: comparison of ultrasonographic estimates versus direct measurements with a dye-dilution technique in human pregnancy. Am J Obstet Gynecol. 1992;167(4):986-994. doi:10.1016/ S0002-9378(12)80025-1
3. Magann EF, Nolan TE, Hess LW, Martin RW, Whitworth NS, Morrison JC. Measurement of amniotic fluid volume: accuracy of ultrasonography techniques. Am J Obstet Gynecol. 1992;167 (6):1533-1537. doi:10.1016/0002-9378(92)91734-R

4. Magann EF, Morton ML, Nolan TE, Martin JN, Whitworth NS, Morrison JC. Comparative efficacy of two sonographic measurements for the detection of aberrations in the amniotic fluid volume and the effect of amniotic fluid volume on pregnancy outcome. Obstet Gynecol. 1994;83 (6):959-962. doi:10.1097/00006250-199406000-00012

5. Horsager R, Nathan L, Leveno KJ. Correlation of measured amniotic fluid volume and sonographic predictions of oligohydramnios. Obstet Gynecol. 1994;83(6):955-958. doi:10.1097/00006250-199406000-00011

6. Magann EF, Nevils BG, Chauhan SP, Whitworth NS, Klausen JH, Morrison JC. Low amniotic fluid volume is poorly identified in singleton and twin pregnancies using the $2 \times 2 \mathrm{~cm}$ pocket technique of the biophysical profile. South Med J. 1999;92(8):802-805. doi:10.1097/00007611-199908000-00011

7. Chauhan SP, Magann EF, Morrison JC, Whitworth NS, Hendrix NW, Devoe LD. Ultrasonographic assessment of amniotic fluid does not reflect actual amniotic fluid volume. Am J Obstet Gynecol. 1997;177 (2):291-297. doi:10.1016/S0002-9378(97)70189-3

8. Hughes DS, Magann EF, Whittington JR, Wendel MP, Sandlin AT, Ounpraseuth ST. Accuracy of the ultrasound estimate of the amniotic fluid volume (amniotic fluid index and single deepest pocket) to identify actual low, normal, and high amniotic fluid volumes as determined by quantile regression. J Ultrasound Med. 2020;39 (2):373-378. doi:10.1002/jum.15116

9. Magann EF, Whitworth NS, Files JC, Terrone DA, Chauhan SP, Morrison JC. Dye-dilution techniques using aminohippurate sodium: do they accurately reflect amniotic fluid volume? J Matern Fetal Neonatal Med. 2002;11(3):167-170. doi:10.1080/jmf.11.3.167.170

10. Brace RA, Wolf EJ. Normal amniotic fluid volume changes throughout pregnancy. Am J Obstet Gynecol. 1989;161(2):382-388. doi:10.1016/0002-9378(89)90527-9

11. Magann EF, Bass JD, Chauhan SP, Young RA, Whitworth NS, Morrison JC. Amniotic fluid volume in normal singleton pregnancies. Obstet Gynecol. 1997;90(4):524-528. doi:10.1016/ S0029-7844(97)00351-7

12. Ounpraseuth ST, Magann EF, Spencer HJ, Rabie NZ, Sandlin AT. Normal amniotic fluid volume across gestation: comparison of statistical approaches in 1190 normal amniotic fluid volumes. $J$ Obstet Gynaecol Res. 2017;43(7):1122-1131. doi:10.1111/jog.13332

13. Magann EF, Perry KG, Chauhan SP, Anfanger PJ, Whitworth NS, Morrison JC. The accuracy of ultrasound evaluation of amniotic fluid volume in singleton pregnancies: the effect of operator experience and ultrasound interpretative technique. J Clin Ultrasound. 1997;25 (5):249-253. doi:10.1002/(SICI)1097-0096(199706)25:5<249:AIDJCU5>3.0.CO;2-D

14. Magann EF, Chauhan SP, Barrilleaux PS, Whitworth NS, McCurley S, Martin JN. Ultrasound estimate of amniotic fluid volume: color Doppler overdiagnosis of oligohydramnios. Obstet Gynecol. 2001;98(1):71-74.

15. Magann EF, Doherty DA, Chauhan SP, Barrilleaux SP, Verity LA, Martin JN. Effect of maternal hydration on amniotic fluid volume. Obstet Gynecol. 2003;101(6):1261-1265.

16. Hughes DS, Whittington JR, Kim H, Gunderman B, Ounpraseuth S, Magann EF. Is there a difference in sonographic estimation of amniotic fluid volume when measuring with the probe perpendicular to the floor compared with perpendicular to the uterine contour? J Obstet Gynaecol Can. 2019;41(9):1295-1301. doi:10.1016/j.jogc.2019.01.017 17. Alfirevic Z, Luckas M, Walkinshaw SA, McFarlane M, Curran R. A randomised comparison between amniotic fluid index and maximum pool depth in the monitoring of post-term pregnancy. $\mathrm{Br}$ $J$ Obstet Gynaecol. 1997;104(2):207-211. doi:10.1111/j.14710528.1997.tb11046.x 
18. Magann EF, Doherty DA, Field K, Chauhan SP, Muffley PE, Morrison JC. Biophysical profile with amniotic fluid volume assessments. Obstet Gynecol. 2004;104(1):5-10. doi:10.1097/01. AOG.0000131618.14176.00

19. Moses J, Doherty DA, Magann EF, Chauhan SP, Morrison JC. A randomized clinical trial of the intrapartum assessment of amniotic fluid volume: amniotic fluid index versus the single deepest pocket technique. Am J Obstet Gynecol. 2004;190(6):1564-1570. doi:10.1016/j. ajog.2004.03.046

20. Chauhan SP, Doherty DD, Magann EF, Cahanding F, Moreno F, Klausen JH. Amniotic fluid index vs single deepest pocket technique during modified biophysical profile: a randomized clinical trial. Am J Obstet Gynecol. 2004;191(2):661-668. doi:10.1016/j.ajog.2004.06.078
21. Kehl S, Schelkle A, Thomas A, et al. Single deepest vertical pocket or amniotic fluid index as evaluation test for predicting adverse pregnancy outcome (SAFE trial): a multicenter, open-label, randomized controlled trial. Ultrasound Obstet Gynecol. 2016;47(6):674-679.

22. Nabhan AF, Abdelmoula YA. Amniotic fluid index versus single deepest vertical pocket as a screening test for preventing adverse pregnancy outcome. Cochrane Database Syst Rev. 2008;2008(3):CD006593.

\section{Publish your work in this journal}

The International Journal of Women's Health is an international, peerreviewed open-access journal publishing original research, reports, editorials, reviews and commentaries on all aspects of women's healthcare including gynecology, obstetrics, and breast cancer. The manuscript management system is completely online and includes a very quick and fair peer-review system, which is all easy to use. Visit http://www.dovepress.com/testimonials.php to read real quotes from published authors. 